\title{
APPLICATION OF A LOGISTIC FUNCTION TO DESCRIBE THE GROWTH OF FODDER GALEGA
}

\author{
Katarzyna Rymuza', Antoni Bombik' \\ 1 University of Natural Sciences and Humanities in Siedlce, Prusa 14, 08-110 Siedlce, Poland, e-mail: katarzyna. \\ rymuza@uph.edu.pl
}

Received: 2016.07.20

Accepted: 2016.10.23

Published: 2017.01.01

\begin{abstract}
It was attempted in the paper to describe the growth of oriental goat's rue (Galega orientalis Lam.) growth by means of a logistic function. The studies demonstrated that the function describes empirical data well as the coefficients of determination obtained ranged between 97 to $98 \%$, depending on the growing season. The estimated function parameters indicate that both the plant height and growth rate were conditioned by thermal conditions and moisture during the growing season. Plants had the longest stems in the year $2010(127.9 \mathrm{~cm})$, and the shortest in $2008(105.9 \mathrm{~cm})$. The maximum growth rate ranged from 2.12 to $3.97 \mathrm{~cm}$ per day in, respectively, 2009 and 2008. Also the inflection point, the point at which plants grew the fastest, depended on the conditions of the growing season.
\end{abstract}

Keywords: oriental goat's rue, logistic function, growth equation, growth rate equation, growth rate.

\section{INTRODUCTION}

Oriental goat's rue (Galega orientalis Lam.) is a plant of the family Fabaceae Lindl., subfamily Fabaoideae, tribe Galegae and subtribe Galeginae. It is only recently that scientists worldwide [Šlepetys, 2003; Baležentienè, 2009, 2011; Egamberdieva et al., 2010; Mikkonen et al., 2011] and in Poland [Deska, 2009; Deska et al., 2012, Kozłowski and Zielewicz, 2013] have started to be interested in the plant. Indigenous to the northern Caucasus, the plant can be found in the wild in forested regions of Georgia, southern Armenia, south-western Azerbaijan and sometimes in the Crimea. Due to the fact that the plant's green parts are rich in protein (the content ranges between 16-27\%), oriental goat's rue is commonly grown in some EU Baltic countries (Estonia, Finland, Latvia) and in Russia. In Poland the species is relatively unpopular, just like in France, Canada, Croatia, Belarus and Serbia where the first attempts are being made to introduce the plant on a wider scale. Studies on the biology of growth and morphological development of the oriental goat's rue, conducted by Raig [2001], Ignaczak [2010] have demonstrated that the development of the plant is a complex process. During the growing season, leaf rosettes are formed on root necks in early spring. When the minimum temperature exceeds $5^{\circ} \mathrm{C}$, plants start to produce aerial stems from root necks that have overwintered, and one-year-old underground roots. During blossoming and pod maturation, cluster tips wither and shrink if rainfall is insufficient. Under the climatic conditions of Poland, pods in main clusters mature in late July. However, if late July is rainy, oriental goat's rue's plants develop secondary and tertiary stems which produce flowers [Deska and Wyrzykowska, 2005; Deska, 2009; Deska et al., 2012].

Similarly to any other plant, the development of oriental goat's rue can be described mathematically by means of indices and functions. The functions that describe the relationship: age-time, are called growth curves and make it possible to include many measurements into one equation based on several parameters which can be interpreted from a biological standpoint. They are 
sigmoid curves consisting of three stages: "exponental" characterized by slow but constantly increasing growth, "linear" when the growth is the fastest till maximum is reached, and the stage of "growing old" when the growth slows [Gregorczyk, 1991; Wesołowska-Janczarek, 1993; Karadavut et al., 2008]. Analysis of plant growth frequently employs the logistic function - a function which is continuous and differentiable at each point in its domain, with an inflection point with respect to which the graph is symmetrical [Tsoularis, 2001; Tsoularis and Wallace, 2002].

The mathematical description of a completed process may contribute to enhanced knowledge of the biology of plant development, indicate moments of optimum agrotechnological actions, help to forecast yields as well as indicate morphological and developmental differences of individuals and the whole population.

The objective of the work was to examine the growth of oriental goat's rue Galega orientalis Lam.) during a 4-year period by means of a logistic function.

\section{MATERIALS AND METHODS}

Analysis of data was based on measurements of stem lengths of oriental goat's rue (Galega orientalis Lam.) cv. Gale which were taken during a four-year period as part of a long-term experiment set up in 2007 at the University of Natural Sciences and Humanities experimental site $\left(52^{\circ} 10^{\prime} \mathrm{N}, 22^{\circ} 17^{\prime} \mathrm{E}\right.$ Poland).

From 2007 to 2010, 70 plants were randomly selected every seven days from the start of growth to the stage of full maturity of pods. The beginning of growth was assumed to be the moment of forming leaf buds on root necks of the plants which overwintered. Thermal conditions and rainfall during the growing seasons are presented in Figures 1 and 2.

The temperature varied in all the study years. Relatively cool spring of 2007 saw a sudden increase in temperature in late April, and high temperatures at the end of the growing season. In the years 2008 and 2010 the beginning of the growing season was characterized by quite low tem-

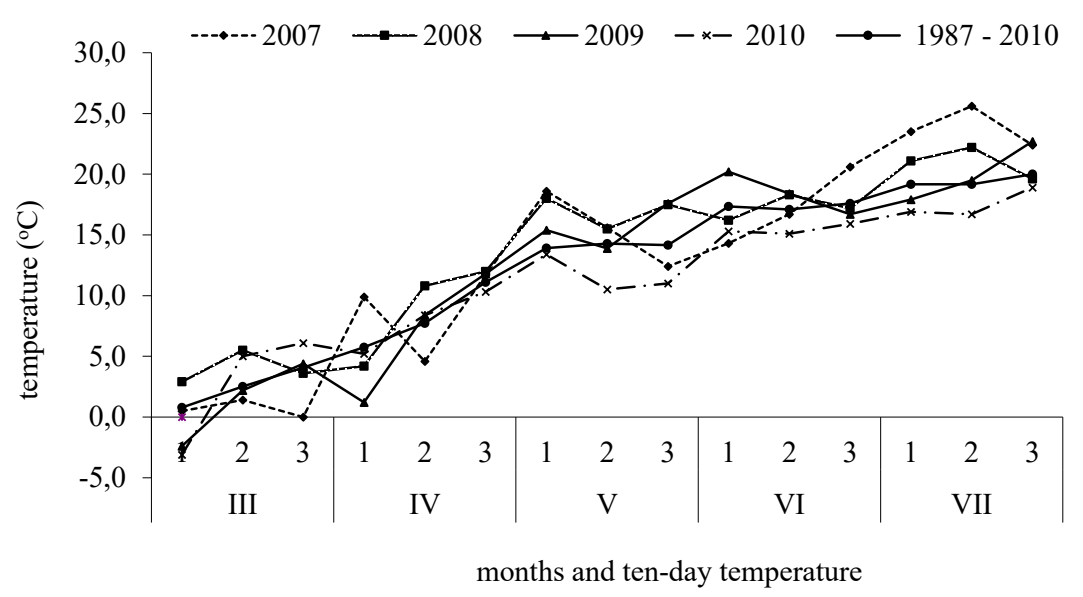

Figure 1. Ten-day and monthly temperatures $\left({ }^{\circ} \mathrm{C}\right)$ in the study years

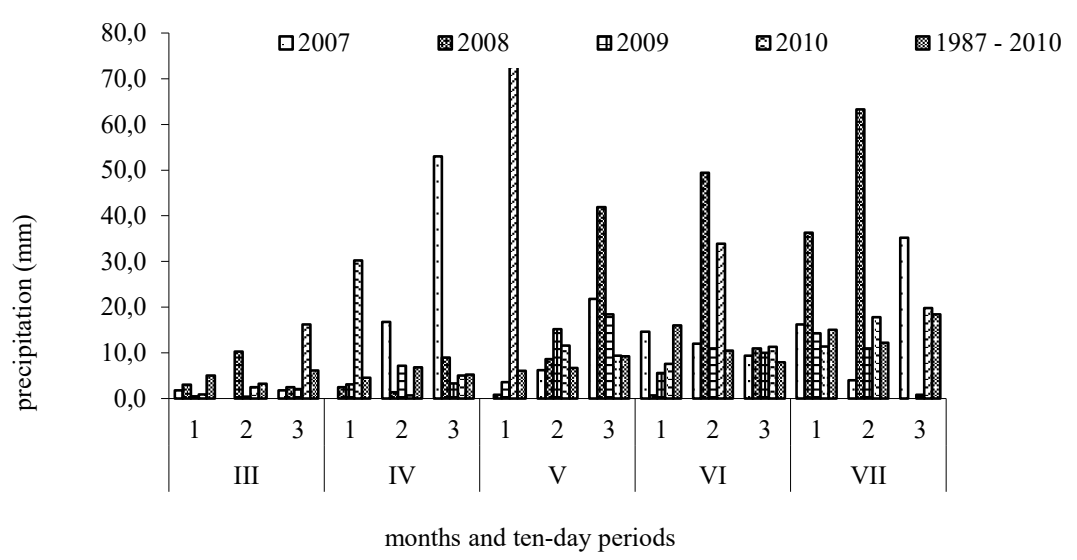

Figure 2. Ten day and monthly precipitation $(\mathrm{mm})$ in the study years 
peratures, around $5^{\circ} \mathrm{C}$, but later they increased steadily. The temperature in the year 2009 was the lowest in the spring and was still around $1{ }^{\circ} \mathrm{C}$ as late as in early April. Then a sudden increase in temperature was observed.

The worst hydrological conditions were recorded in 2007 and 2009 when the precipitation did not exceed $200 \mathrm{~cm}$ during the growing season. Moreover, it was unevenly distributed over time. With this respect, the best year was 2010 when the high rainfall was also evenly distributed and, as a result, met the needs of plants.

The following function was used to describe the growth of oriental goat's rue [Richards, 1969]:

$$
\mathrm{y}(\mathrm{t})=\frac{\mathrm{a}}{1+\mathrm{b} \cdot \mathrm{e}^{-\mathrm{k} \cdot \mathrm{t}}}
$$

where: $y(t)$ - denotes plant's height on day $t$,

$a$ - the value of asymptote,

$b-$ an integration constant and

$k$ - the index of growth rate.

The terms $\mathrm{a}, \mathrm{k}$ and $\mathrm{b}$ are somehow interdependable. If $\mathrm{k}$ values are high, a values are low and describe small plants. By contrast, low $\mathrm{k}$ values generate high values, which is typical of high plants. Values of the parameter $b$ depend on initial values and, in general, higher plants have got lower b values.

Equations of functions of average growth were estimated for each year separately. The criterion of goodness of fit was the determination coefficient $\mathrm{R}^{2}$, which is frequently used for this purpose, calculated following the formula [Seber and Wild, 1989; Ryan, 1997]:

$$
\mathrm{R}^{2}=1-\frac{\mathrm{SSE}}{\mathrm{SST}}
$$

in which:

$$
\operatorname{SSE}=\sum_{i=1}^{n}\left(y_{i}-f_{i}\right)^{2}, \quad S S T=\sum_{i=1}^{n}\left(y_{i}-\bar{y}\right)^{2},
$$

where: $y_{i}-$ experimental data;

$f_{i}$ - values of the function fitted corresponding to the values $y_{i}$,

$\bar{y}$ - arithmetical mean of the experimental data.

Values of the coefficient are close to 1 when the fit is good, and they are close to 0 when the fit is poor. If a function examined completely disagree with the experimental data, the coefficient may be negative, which indicates that the function should be discarded because it is not the appropriate model to describe the process [Bochniak and Wesołowska-Janczarek, 2006].
Moreover, the equation of growth rate was calculated in addition to the theoretical initial value of growth and inflection points, according to the formulae [Gregorczyk, 1991]:

- equation of growth rate:

$$
\frac{d y}{d t}=\frac{k}{a} \cdot y(t) \cdot(a-y(t))
$$

- theoretical initial value of growth:

$$
\mathrm{y}_{0}=\frac{\mathrm{a}}{1+\mathrm{b}}
$$

- coordinates of the inflection point of the function:

$$
\mathrm{t}_{\mathrm{i}}=\frac{\ln \mathrm{b}}{\mathrm{k}}, \quad \mathrm{y}\left(\mathrm{t}_{\mathrm{i}}\right)=0,5 \cdot \mathrm{a}
$$

In order to compare the growth patterns in individual years, the function was linearized following the formula: $\operatorname{lnb}-\mathrm{k} \times \mathrm{t}$. Next, the hypothesis was checked whether or not the slopes of strait lines are equal so as to find out if the course of the straight lines examined is the same. The hypothesis $\mathrm{H}_{0}=\mathrm{k}_{1}=\mathrm{k}_{2}=\mathrm{k}_{3}=\mathrm{k}_{4}$ was checked using Tukey's test following Elandt [1964].

All the calculations were performed using Statistica 9.0 and the Excel spreadsheet.

\section{RESULTS}

Figure 1 shows the growth of goat's rue in the study years. It demonstrates that the growth was the best in 2010 when precipitation distribution coincided with the water needs of plants. Also function parameters, describing growth equations and growth rate equations, confirm this finding (Table 1, 2 and Figure 3). In 2010 the plants had the highest theoretical asymptotic value (parameter a) and low values of coefficients $k$ and $b$.

In 2010 oriental goat's rue plants as early as after 42 days of growth reached the inflection points at the stem length of $64 \mathrm{~cm}$ and the maximum growth rate of $3.45 \mathrm{~cm} \cdot$ day $^{-1}$. Similar growth was observed in the year 2008 when stems had the lowest theoretical initial value $(0.131 \mathrm{~cm})$ and asymptotic maximum length $(105.95 \mathrm{~cm})$. However, conditions during the growing season (rainfall met the water needs of plants) resulted in the inflection point which was by three days longer compared with 2010 , the growth rate being the highest as it was almost $4 \mathrm{~cm}$ per day. 
Table 1. Maximum empirical value reached by plants and logistic function parameters which approximate the elongation of goat's rue plants in the study years

\begin{tabular}{|c|c|c|c|c|c|c|c|c|}
\hline \multirow{2}{*}{ Year } & \multirow{2}{*}{$\mathrm{y}_{\max }(\mathrm{cm})$} & \multirow{2}{*}{$\mathrm{y}_{\mathrm{o}}(\mathrm{cm})$} & \multicolumn{3}{|c|}{ Function parameters } & \multirow{2}{*}{$\mathrm{t}_{\mathrm{i}}(\mathrm{day})$} & \multirow{2}{*}{$\mathrm{y}\left(\mathrm{t}_{\mathrm{i}}\right)(\mathrm{cm})$} & \multirow{2}{*}{$\frac{\mathrm{dy}}{\mathrm{dt}}\left(\mathrm{cm} \cdot \mathrm{day}{ }^{-1}\right)$} \\
\cline { 4 - 8 } & & & $\mathrm{a}$ & $\mathrm{b}$ & $\mathrm{k}$ & & 53.8 & 2.96 \\
\hline 2007 & 108.0 & 0.268 & 107.7 & $2.95 \times 10^{2}$ & $1.11 \times 10^{-1}$ & 51.7 & 52.9 & 3.97 \\
\hline 2008 & 108.1 & 0.131 & 105.9 & $8.06 \times 10^{2}$ & $1.50 \times 10^{-1}$ & 44.6 & 53.0 & 2.12 \\
\hline 2009 & 104.9 & 3.04 & 106.0 & $5.09 \times 10^{1}$ & $0.80 \times 10^{-1}$ & 49.1 & 5.1 & 3.45 \\
\hline 2010 & 129.1 & 1.38 & 128.0 & $9.19 \times 10^{1}$ & $1.11 \times 10^{-1}$ & 41.9 & 64.0 & \\
\hline
\end{tabular}

$\mathrm{y}_{\max }$ - empirical maximum growth, $\mathrm{y}_{\mathrm{o}}-$ theoretical initial growth, $\mathrm{t}_{\mathrm{i}}, \mathrm{y}\left(\mathrm{t}_{\mathrm{i}}\right)$ - coordinates of inflection point, $\frac{\mathrm{dy}}{\mathrm{dt}}-$ maximum growth rate

Table 2. Goat's rue growth equations and growth rate equations in the study years

\begin{tabular}{|l|l|l|l|}
\hline Years & \multicolumn{1}{|c|}{ Growth equation } & $R^{2}$ & \multicolumn{1}{|c|}{ Growth rate equation } \\
\hline 2007 & $\mathrm{y}=107.7 \times\left[1+2.95 \times 10^{2} \times \exp \left(-1.11 \times 10^{-1} \mathrm{t}\right)\right]^{-1}$ & 0.998 & $\mathrm{dy} / \mathrm{dt}=10.3 \times 10^{-4} \times \mathrm{y}(\mathrm{t}) \times[107.7-\mathrm{y}(\mathrm{t})]$ \\
\hline 2008 & $\mathrm{y}=105.9 \times\left[1+8.06 \times 10^{2} \times \exp \left(-1.50 \times 10^{-1} \mathrm{t}\right)\right]^{-1}$ & 0.997 & $\mathrm{dy} / \mathrm{dt}=14.2 \times 10^{-4} \times \mathrm{y}(\mathrm{t}) \times[105.9-\mathrm{y}(\mathrm{t})]$ \\
\hline 2009 & $\mathrm{y}=106.0 \times\left[1+5.09 \times 10^{1} \times \exp \left(-0.80 \times 10^{-1} \mathrm{t}\right)\right]^{-1}$ & 0.998 & $\mathrm{dy} / \mathrm{dt}=7.8 \times 10^{-4} \mathrm{y}(\mathrm{t}) \times[106.0-\mathrm{y}(\mathrm{t})]$ \\
\hline 2010 & $\mathrm{y}=127.9 \times\left[1+9.19 \times 10^{1} \times \exp \left(-1.11 \times 10^{-1} \mathrm{t}\right)\right]^{-1}$ & 0.998 & $\mathrm{dy} / \mathrm{dt}=8.7^{-4} \times \mathrm{y}(\mathrm{t}) \times[127.9-\mathrm{y}(\mathrm{t})]$ \\
\hline
\end{tabular}
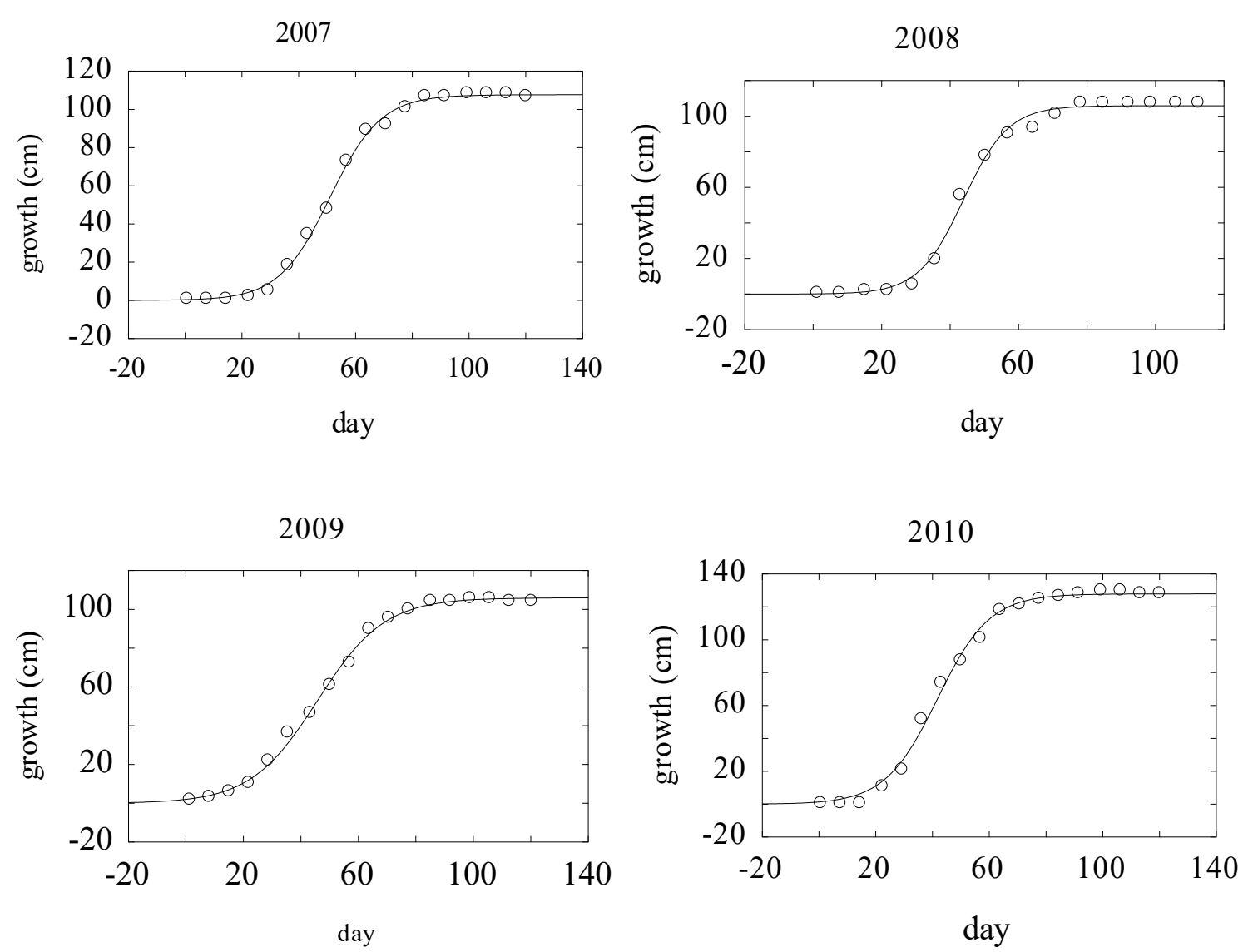

Figure 3. Fit of estimated functions to the empirical data in individual study years

The year 2009 was the least beneficial for goat's rue plants as it was characterised by unfavourable thermal and water conditions (the precipitation sum did not exceed $200 \mathrm{~mm}$ ). Low temperature for a long time at the start of growth did not stimulate the growth of goat's rue. Over the four-year period plants had the lowest empirical length of stems -104.86 , the lowest growth index $\mathrm{k}$ and the lowest theoretical maximal growth rate $\left(2.12 \mathrm{~cm}\right.$ in the $79^{\text {th }}$ day of growth and at the stem 
length of $53 \mathrm{~cm}$ ) (Table 1,2). The plants of goat's rue reached the inflection point as late as on the $52^{\text {th }}$ day of growth and height of $54 \mathrm{~cm}$. It was associated with maximum growth rate of almost 3 $\mathrm{cm}$ per day (Table 1, 2, Figure 4).

After linearization different lines were obtained, which was statistically confirmed. The value of $F$ (9.40) was higher than the critical value $\mathrm{F}$ (3.13) so the hypothesis assuming equal regression linear coefficients $(k)$ was refuted and the alternative hypothesis was accepted, which meant that the lines were not parallel (Figure 5).

The function applied is a good representation of the process of rue's plant growth, as indicated by high determination coefficients as well as figures demonstrating how well the estimated curves fit the empirical data (Table 2, Figure 6).

\section{DISCUSSION}

Plant growth is a complicated process which can be described by suitable mathematical func- tions. So far, many mathematical models were developed which reflect the growth process of plants and their individual organs. Curry [1971] as well as Curry and Chen [1971] suggested a mathematical growth model of maize roots, stem and leaves. Baker et al. [1972] and Pyda [1977] developed the growth model of, respectively, cotton and rape plants. As science progresses, the already existing models are being replaced by new ones which produce more and more reliable values (better reflect real values) [France, 1984]. Growth processes may be described, similarly to this and other works Seidler and Gregorczyk [1986], Mustears [1989], Villegas et al. [2001], Damgaard et al. [2002], by the logistic function. Also Karadavut et al. [2008] used the logistic function to develop the model of wheat growth. As the logistic function fits empirical data well in this work, it may indicate that the function can be used to describe the growth and development of goat's rue. Also Damgaard and Weiner [2008] and Karadavut [2009] reported a good fit of logistic curve to empirical data. An appropriately

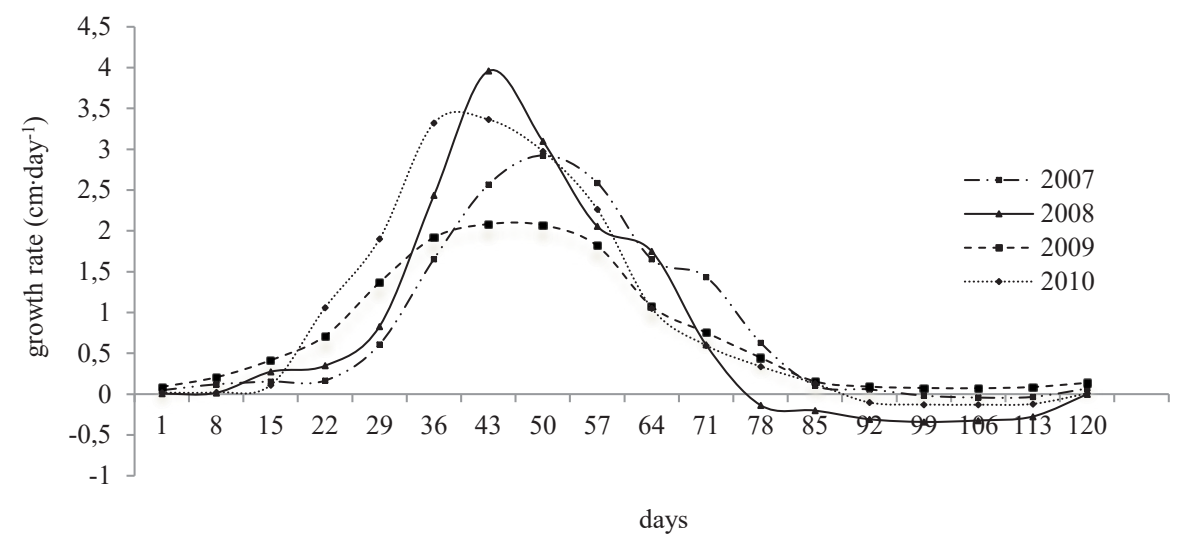

Figure 4. Theoretical equations of growth rate in the study years

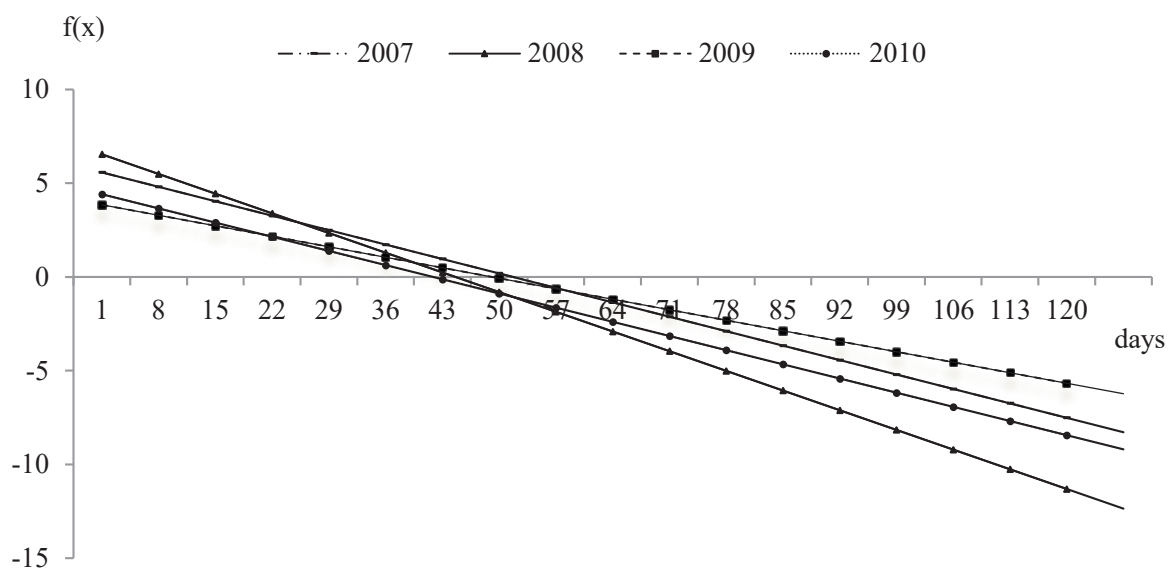

Figure 5. Plant growth equations in the study years (following linearization) 


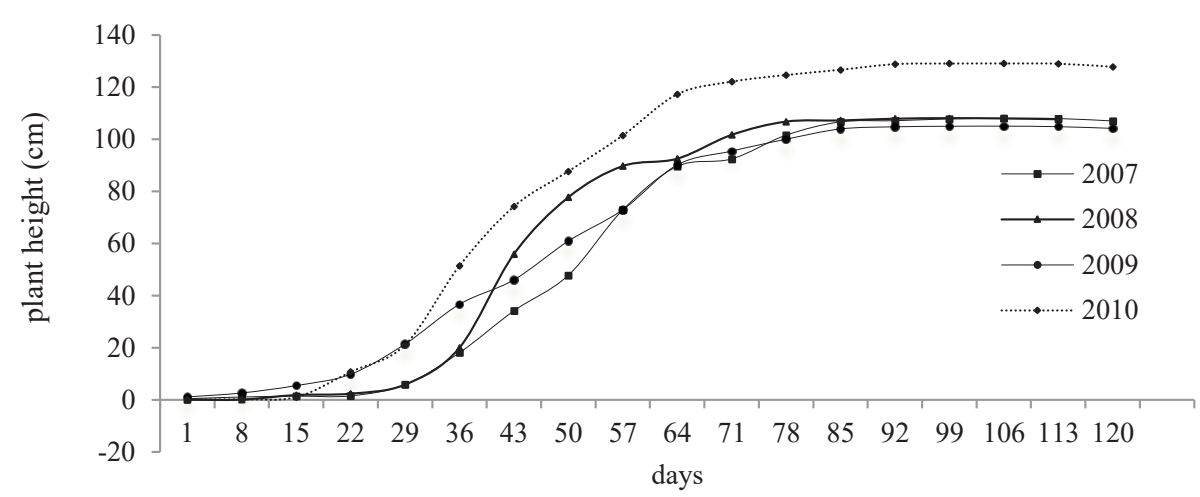

Figure 6. Empirical plant growth in individual study years

adjusted model (mathematical function) makes it easy to compare experimental data and sometimes enables forecasting plant growth.

Similarly to Gregorczyk [1991], there was observed varied dynamics of plant elongation in individual years, which was indirectly supported by the statistical comparison of lines of the estimated functions. This indicates that weather conditions had a marked impact on the growth of goat's rue which requires quite a lot of water due to abundant canopy, similar findings reported by Patterson [1993]. The maximum theoretical growth rates calculated in this work ranged between 2.12 and $3.97 \mathrm{~cm}$ per days in 2009 and 2008, respectively. Also inflection points were different in individual years. The longest inflection point was observed in 2009 and the shortest in 2010.

\section{CONCLUSIONS}

1. The logistic function enables a good approximation of theoretical data to empirical data, which is supported by high values of determination coefficients describing how well the growth equations determined fit the experimental data.

2. Weather conditions in the individual study years differently influenced the growth and development of goat's rue, as indicated by growth function parameters, growth rate equations and linearized growth equations.

3. Asymptotic growth values ranged from 105.9 to $127.9 \mathrm{~cm}$, depending on the growing season, and, in general, they were lower than the maximum empirical values.

4. In individual years goat's rue plants differed as to the maximum theoretical rate of growth and the date at which the inflection point was observed. The extreme values were, respectively $1.85 \mathrm{~cm}$ per day and 10 days. In 2010, the inflection point was observed on the $42^{\text {th }}$ day, and in 2007 on the $52^{\text {th }}$ day of growth. Due to the conditions of the year 2008 (rainfall which met plants' needs), the theoretical growth rate of goat's rue was the greatest and reached $4 \mathrm{~cm}$ per day whereas in 2009 the maximum growth per day was slightly above $2 \mathrm{~cm}$.

\section{REFERENCES}

1. Baker D.N., Hesketh J. D., and Duncan W.G., 1972. Simulation of growth and yield in cotton. Gross photosyntesis, respiration ar growth. Crop Science, 12: 431-435.

2. Baležentienė L., 2011. Introduction and agro economical value of Galega orientalis Lam. 3rd International Symposium on Weeds and Invasive Plants, October 2-7, 2011 in Ascona, Switzerland.

3. Baležentienè L., 2009. Bioassay of phenolics accumulation and activity in fodder galega (Galega orientalis Lam.) at different development stages. Agriculture, 96, 170-181.

4. Bochniak A. and Wesołowska-Janczarek M., 2006. A problem of fitting a common curve for two replications on example of sprouting process of corn seeds stimulated with magnetic field. Inżynieria Rolnicza, 5, 39-47.

5. Curry R.B. and Chen L.H., 1971. Dynamic simulation of plant growth. Part II. Incorporation of actual daily weather and partitioning of net photosynthate. Transactions of the ASAE, 14, 1170-1174.

6. Curry R.B., 1971. Dynamic simulation of plant growth. Part I. Development of a model. Transactions of the ASAE, 14, 946-959.

7. Damgaard Ch. and Weiner J., 2008. Modeling the growth of individuals in crowded plant popula- 
tions. Journal of Plant Ecology, 1 (2), 111-116.

8. Damgaard Ch., Weiner J. and Nagashima H., 2002. Modeling the growth of individuals in plant populations: growth curves of Chemopodium album at two densities. Journal of Plant Ecology, 90, 666-671.

9. Deska J. and Wyrzykowska M., 2005. Application of the path method to estimate crop components in seed production of goat's rue (Galega orientalis Lam.). 51. Biom. Koll., Biometrie 2005, Halle Marz 2005, 112.

10. Deska J., 2009. Some problems of fodder galega (Galega orientalis Lam.) growing for seed in climatic conditions of the Siedlce Upland (in Polish). Wyd. AP w Siedlcach. Siedlce, 104 pp.

11. Deska J., Bombik A. and Rymuza K., 2012. The effect of hydro-thermal conditions on the seed yield structure of fodder galega (Galega orientalis Lam.). Water-Environment-Rural Areas, 12 (2), 61-76.

12. Egamberdieva D., Berg G., Lindström, K. and Räsänen L.A., 2010. Co-inoculation of Pseudomonas spp. with Rhizobium improves growth and symbiotic performance of fodder galega (Galega orientalis Lam.). European Journal of Soil Biology, 46, 3-4, 269-272.

13. Elandt R., 1964. Mathematical statistics applied to agricultural experiments. PWN Warszawa, Warszawa, $595 \mathrm{pp}$.

14. Gregorczyk A., 1991. The logistic function-its application to the description and prognosis of plant growth. Acta Societatis Botanicorum Poloniae, 60(1-2), 67-76.

15. Ignaczak S., 2010. Productivity of seed plantations of fodder galega (Galega orientalis Lam.) in extensive utilization. Journal of Research and Applications in Agricultural Engineering, 55(3), 122-127.

16. Karadavut U., 2009. Non linear models for growth curves triticale plants under irrigation conditions. Turkish Journal of Field Crops, 4 (2), 105-110.

17. Karadavut U, Kayi S.A., Palta Ç. and Okur O., 2008. A Growth Curve Application to Compare Plant Heights and Dry Weights of Some Wheat Varieties. American-Eurasian Journal of Agricultural \& Environmental Sciences, 3 (6), 888-892.

18. Kozłowski S., Zielewicz W., 2013. Occurrence of organic constituents in goat's rue taking into con- sideration its fodder utilization. Water-Environment-Rural Areas, 44 (4), 65-76.

19. Mikkonen E., Kondo K., Lappi K., Wallenius K., Lindström, Hartikainen H. and Suominen L., 2011. Contaminant and plant-derived changes in soil chemical and microbiological indicators during fuel oil rhizoremediation with Galega orientalis. Geoderma, 160 (3-4), 336-346.

20. Mustears H..J.W., 1989. A dynamic equation for plant interaction and application to yield-densitytime relations. Annals of Botany, 64, 521-531.

21. Patterson D.T., 1993. Effects of day and night temperature on goat's rue (Galega officinalis) and alfalfa (Medicago sativa) growth. Weed Science, 41, 38-45.

22. Pyda M., 1977. Mathematical model of rape growth (in Polish). Nowe Rolnictwo, 5, 12-13.

23. Raig H., 2001. Cutting time and frequency. In: H. Nommsalu (Editor) Fodder galega. Saku. Estonian. Research Institute of Agriculture, 55-57.

24. Richards F.J., 1969. A flexible growth function for empirical use. Journal of Experimental Botany, 10: 290-300.

25. Ryan T.P., 1997. Modern Regression Methods. Wiley \& Sons, New York, 672 pp.

26. Seber G.A.F. and Wild C.J., 1989. Nonlinear regression. Wiley \&Son, New York, 768 pp.

27. Seidler M. and A. Gregorczyk, 1986. A mathematical description of maize leaf area growth a logistic curve. Acta Agrobotanica, 39(2), 359-365.

28. Šlepetys J., 2003. Longevity of fodder galega and grown for forage and seed on a low moor soil with removed peat layer. Agricultura, 84, 92-103.

29. Tsoularis A. and Wallace J., 2002. Analysis of logistic growth models. Mathematical Biosciences, 179, 21-55.

30. Tsoularis A., 2001. Analysis of Logistic Growth Models. Res. Lett. Inf. Math. Sci., 2, 23-46.

31. Villegas D., Aparicio N., Blanco R., and Royo C., 2001. Biomass accumulation and main stem elongation of durum wheat grown under Mediterranean conditions. Annals of Botany, 88, 617-627.

32. Wesołowska-Janczarek M., 1993. Growth curves a review and new problems. Biometrical Letters, 30, 73-96. 